\title{
Long-term performance of solar-assisted heat pump water heater
}

\author{
B.J. Huang*, C.P. Lee \\ Department of Mechanical Engineering, National Taiwan University, Taipei, Taiwan, ROC
}

Received 8 September 2002; accepted 30 July 2003

\begin{abstract}
A long-term reliability test of an integral-type solar-assisted heat pump water heater (ISAHP) was carried out. The prototype has been running continuously for more than $13,000 \mathrm{~h}$ with total running time $>20,000 \mathrm{~h}$ during the past $5 \mathrm{yr}$. The measured energy consumption is $0.019 \mathrm{kWh} / 1$ of hot water at $57{ }^{\circ} \mathrm{C}$ that is much less than the backup electric energy consumption of the conventional solar water heater.
\end{abstract}

(C) 2003 Elsevier Ltd. All rights reserved.

Keywords: Solar energy; Heat pump; Solar heat pump

\section{Introduction}

The direct expansion solar-assisted heat pump water heater has a better performance since the Rankine refrigeration cycle is directly coupled with a solar collector that acts as an evaporator and the refrigerant directly expands inside the evaporator to absorb the solar energy [1-3]. The research group at the New Energy Center, Department of Mechanical Engineering, National Taiwan University, started to develop an integral-type solar-assisted heat pump water heater (ISAHP) [4] in 1997. The ISAHP integrates all components of the machine into a single package that can be completely fabricated in the factory. No field assembly is required except the connection of a water pipe line and electric power connector. With proper design, the ISAHP absorbs heat simultaneously from solar radiation and ambient air [5]. Cost reduction as well as better thermal performance can be achieved. However, the evaporator of the ISAHP will absorb solar energy at an

\footnotetext{
* Corresponding author. Tel.: +886-2-2362-4790; fax: +886-2-2364-0549.

E-mail address: bjhuang@seed.net.tw (B.J. Huang).
} 


\section{Nomenclature}

$E_{\mathrm{m}} \quad$ electric energy consumption of ISAHP per liter of hot water at $57{ }^{\circ} \mathrm{C}$ $(\mathrm{kWh} / 1)$

$H_{\mathrm{t}} \quad$ daily total solar radiation incident on horizontal surface $\left(\mathrm{MJ} / \mathrm{m}^{2}\right.$ day)

$m_{\mathrm{h}} \quad$ daily hot water load (1/day)

$T_{\mathrm{a}} \quad$ daily-mean ambient temperature at operation of ISAHP $\left({ }^{\circ} \mathrm{C}\right)$

unsteady state due to the unsteadiness of the solar incident radiation and outdoor weather variation. This will cause the heat pump to run under much more severe conditions than conventional heat pumps such as air conditioners. The reliability thus remains a big question for a direct expansion solar-assisted heat pump water heater. In order to understand the long-term energy efficiency as well as the reliability of the ISAHP built in 1997 (ISAHP-1), a long-term performance test was carried out.

\section{Design of ISAHP}

The ISAHP consists of a Rankine cycle unit, a collector/evaporator unit, and a heat exchanger/condenser unit that combines the condenser of the Rankine cycle and the heater of a thermosyphon loop (Fig. 1) [4]. The ISAHP absorbs energy from solar radiation and ambient air simultaneously [5] and transports the heat to the storage tank through the Rankine cycle. For obtaining high reliability and reducing cost, a heat exchanger/condenser unit is designed with a thermosyphon loop to transfer the heat from the condenser to the water storage tank. The condenser releases condensing heat from the Rankine cycle to the waterside of the heat exchanger for producing a natural-circulation flow in the thermosyphon loop. The compressor is the only component that has moving part in the ISAHP.

In ISAHP-1, the unglazed solar collector is divided into four parts: top $(50 \times 74$ $\mathrm{cm})$, front $(50 \times 120 \mathrm{~cm})$ and two $\operatorname{sides}(50 \times 60 \mathrm{~cm})$. The total collector area is 1.44 $\mathrm{m}^{2}$. The capacity of the water storage tank is 1051 . ISAHP-1 utilizes an R134a compressor $(250 \mathrm{~W}, 110 \mathrm{VAC})$ commonly used in household refrigerators for the Rankine cycle. A counter-flow heat exchanger is used as the condenser/heat exchanger unit.

\section{Instrumentation}

This laboratory-made ISAHP (ISAHP-1) (Fig. 2) was equipped with some instruments to monitor long-term performance. To simulate the daily hot water load, we installed an automatic hot water drainage system in order to discharge the 


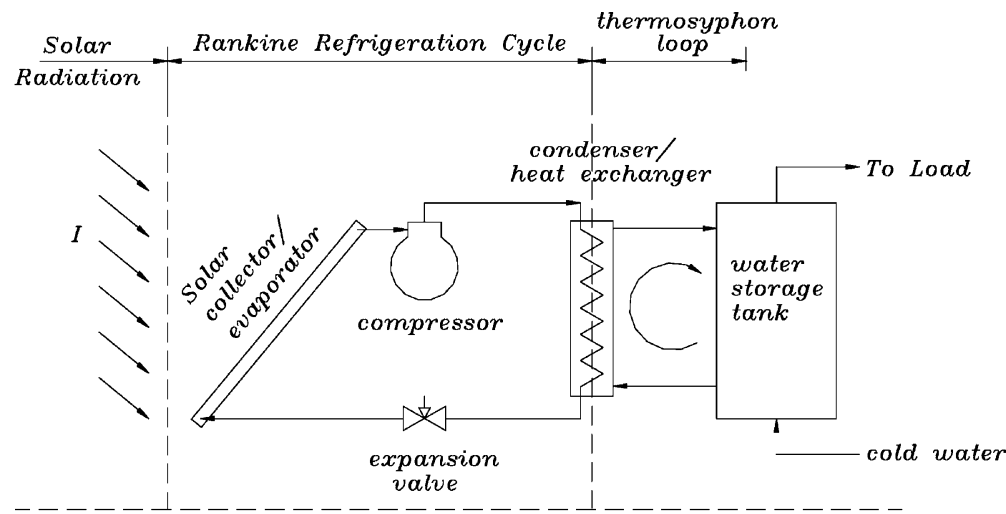

Fig. 1. Schematic diagram of an ISAHP.

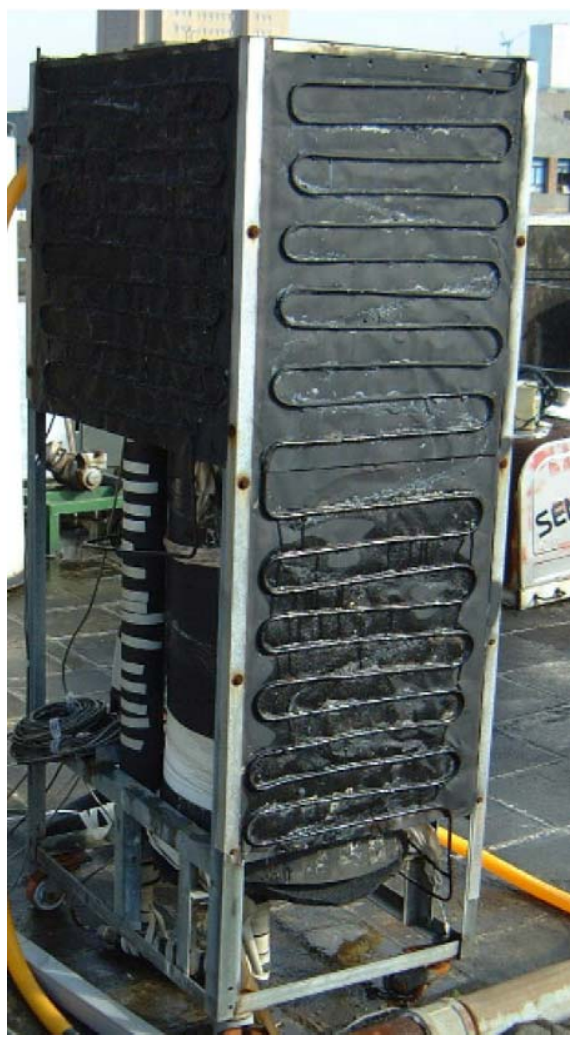

Fig. 2. Prototype of ISAHP. 
hot water and feed cold water into the water tank every day before sunrise. The feed water is from a city water line that has a temperature of about $2-4{ }^{\circ} \mathrm{C}$ below the ambient air temperature. However, the water temperature in the tank at the startup moment of ISAHP-1 (daily initial water temperature) will increase significantly if the hot water produced before the day (105 1) is not completely used, i.e. $m_{w}<1051 /$ day. The daily quantity of drained hot water is around 801 , that is about $80 \%$ of the designed capacity.

A temperature controller is used to shut down the heat pump when water temperature has reached the designated value. The water temperature setting was $57^{\circ} \mathrm{C}$ in the test. A power meter was installed to record the total electric energy consumption of ISAHP-1 during operation. A water meter was also installed to measure the total water consumption.

\section{Long-term performance results of ISAHP}

ISAHP-1 has been running continuously since January 1, 2001. No mechanical failure has ever occurred for a continuous operation of more than 13,000 h until the end of June 2002, with a total running time of $>20,000 \mathrm{~h}$ during the past $5 \mathrm{yr}$ including the research period. This is due to fact that ISAHP-1 has only one moving part, i.e. Freon compressor. The machine will be highly reliable if the system was well designed with proper sizing of all the components. ISAHP-1 has shown itself to be a good design.

The electricity consumption per liter of hot water at $57{ }^{\circ} \mathrm{C}, E_{\mathrm{m}}$, is mostly between 0.01 and $0.03 \mathrm{kWh} / 1$, with an average value $0.019 \mathrm{kWh} / 1$ (Fig. 3). $E_{\mathrm{m}}$ is larger at cloudy or rainy days with low solar radiation as shown in Fig. 4 that is

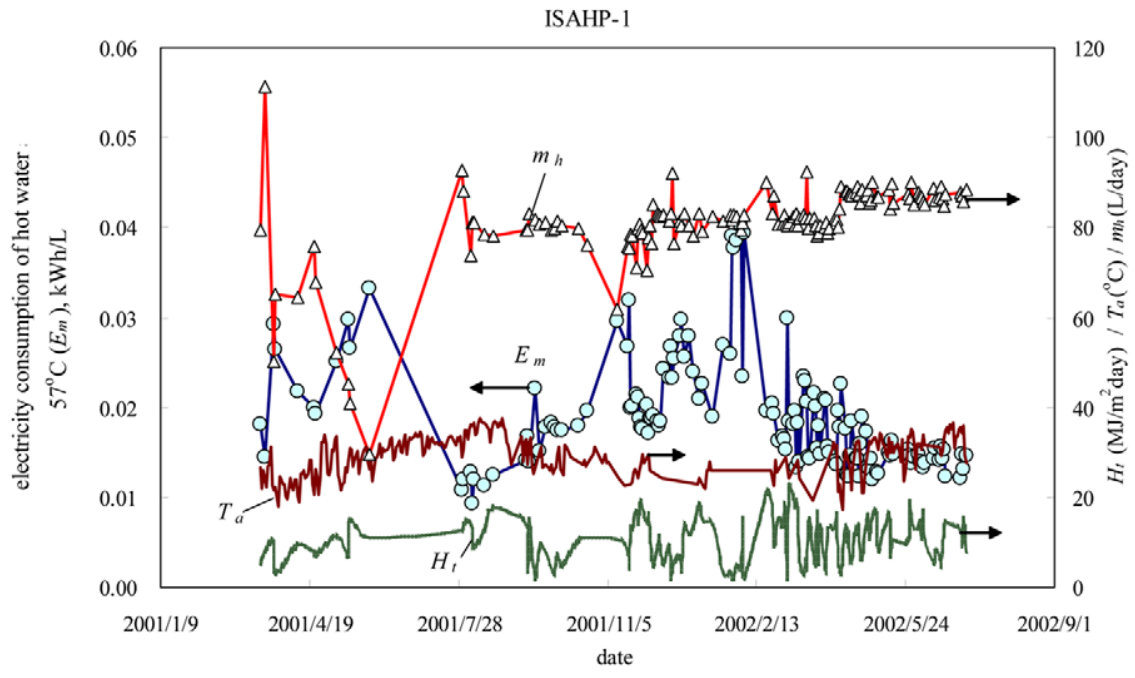

Fig. 3. Long-term performance test results of ISAHP-1. 


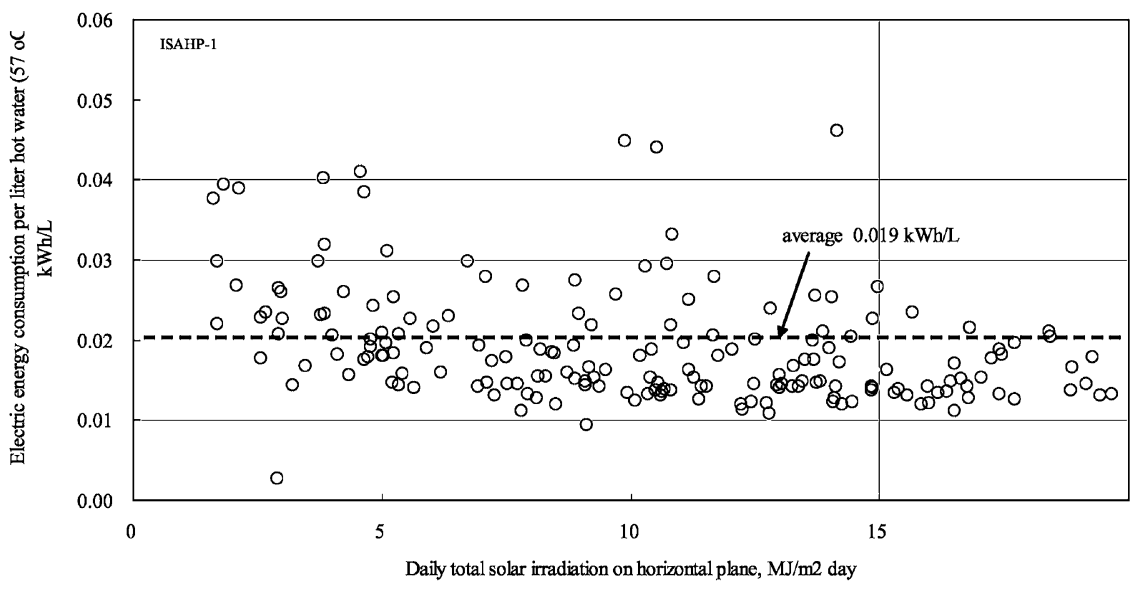

Fig. 4. Variation of electricity consumption with solar irradiation.

directly converted from the results of Fig. 3. At higher solar irradiation $\left(H_{\mathrm{t}}>5\right.$ $\mathrm{MJ} / \mathrm{m}^{2}$ day), $E_{\mathrm{m}}$ approximates a constant value. $E_{\mathrm{m}}$ also increases with decreasing daily hot water load $m_{\mathrm{w}}$. The abnormal test results with higher $E_{\mathrm{m}}$ as shown in Fig. 3 are due to low $m_{\mathrm{w}}$ that is caused by an adjustment problem of the monitoring system at the early stage of the long-term performance test. Low daily hot water load $m_{\mathrm{w}}$ will increase the daily initial water temperature in the tank and decrease the COP as well as $E_{\mathrm{m}}$ for ISAHP [4]. This result also indicates that ISAHP must be designed to properly meet the daily hot water load requirement. Oversized design in hot water supply capacity will cause the energy efficiency to drop significantly.

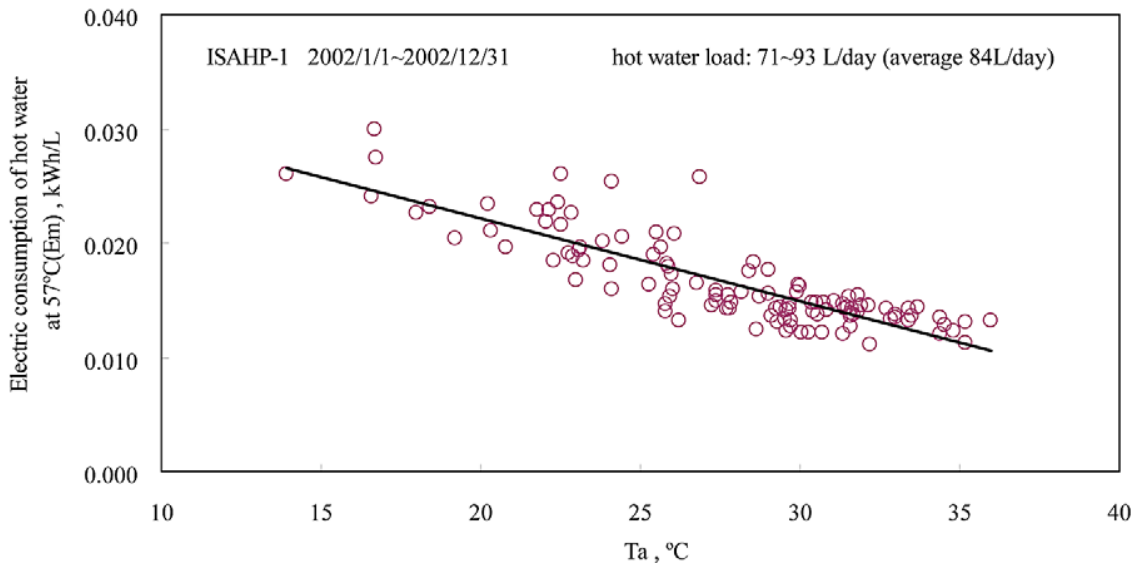

Fig. 5. Variation of electricity consumption with mean daily ambient temperature. 


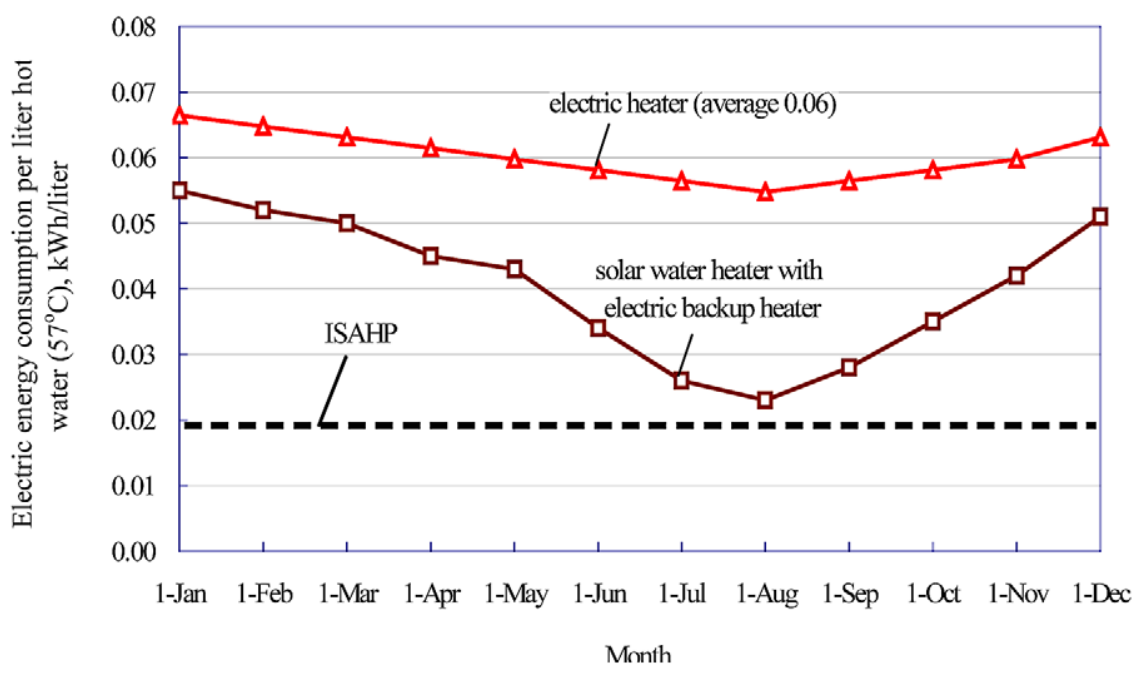

Fig. 6. Electricity consumption of various water heaters.

For an approximately constant hot water load (71-93 1/day, average 84 1/day), $E_{\mathrm{m}}$ drops linearly with increasing ambient temperature $T_{\mathrm{a}}$ as shown in Fig. 5. This indicates that the energy consumption of ISAHP-1 changes more sensitively with ambient temperature $T_{\mathrm{a}}$. $E_{\mathrm{m}}$ becomes higher at cold days (lower $T_{\mathrm{a}}$ ).

The electricity consumption of the conventional solar hot water heating system using electric backup heater ranges from 0.02 to $0.05 \mathrm{kWh} / 1$. A long-term field test for electric and conventional solar heaters was also carried out in the laboratory. It shows that ISAHP-1 consumes much less electricity than the others (Fig. 6). The present study verifies that ISAHP has a very low energy consumption and high reliability even under long-term severe outdoors operating conditions subject to very rough variations of solar incident radiation intensity, wind speed/direction, ambient temperature and rain etc.

\section{Conclusion}

The present study measured the long-term performance of an ISAHP continuously for longer than $1.5 \mathrm{yr}(>13,000 \mathrm{~h})$. The total accumulated operating time for the prototype is over $20,000 \mathrm{~h}$ during the past $5 \mathrm{yr}$. No machine failure has ever occurred. This is due to the good engineering design of ISAHP-1 with only one moving part (compressor) and with good sizing of all the components. The life test is still going on and the expected total lifetime for the prototype ISAHP-1 will be longer than $6 \mathrm{yr}$. The average energy consumption of ISAHP-1 is $0.019 \mathrm{kWh} / 1$ of hot water at $57{ }^{\circ} \mathrm{C}$ that is much less than the backup electric energy consumption of the conventional solar water heater and the pure electric heater. The present 
study has verified that ISAHP is very reliable if it is carefully designed. The commercialization of ISAHP is now underway.

\section{Acknowledgements}

The present study was supported by the Energy Commission, Ministry of Economic Affairs, Taiwan, and by National Science Council, Taiwan, through grant no. NSC89-2212-E-002-072 for the heat pump technology.

\section{References}

[1] Chartuvedi SK, Chiang YF, Roberts AS. Analysis of two-phase flow solar collectors with applications to heat pump. ASME Paper 80-WA/Sol-32; 1980.

[2] Chaturvedi SK, Shen JY. Thermal performance of a direct expansion solar-assisted heat pump. Solar Energy 1984;33(2):155-62.

[3] Ito S, Miura N, Wang K. Performance of a heat pump using direct expansion solar collectors. Solar Energy 1999;65(3):189-96.

[4] Huang BJ, Chyng JP. Integral-type solar-assisted heat pump water heater. Journal of Renewable Energy 1998;16:731-4.

[5] Huang BJ, Chyng JP. Performance characteristics of integral type solar-assisted heat pump. Solar Energy 2001;71(6):403-14. 